\title{
High-dimensional Assembly Depending on Polyoxoanion Templates, Metal ion Coordination Geometries, and Flexible Bis(imidazole) Ligand
}

Baoxia Dong, Jun Peng*, Carlos J. Gómez-García, Samia Benmansour, Hengqing Jia, Ninghai Hu

Corresponding author: jpeng@nenu.edu.cn (J.Peng)

\section{Contents:}

1. The comparison of powder X-ray diffraction of compound $\mathbf{3}$ with that of compound 1; Page S1.

2. The confirmation of the molecular formulas; Page S1-S2.

3. Thermogravimetric analyses of compounds 1-5; Page S2-S3.

4. Figure S1. Illustration of the two sorts of four-membered circuits of $\mathrm{Co}_{4}(\mathrm{bbi})_{4}$ in $\mathbf{1}$ with dimensions of $c a .15 .1 \AA$ x $15.1 \AA$ for I and $c a .5 .9 \AA$ x $5.9 \AA$ for II; Page S3.

5. Figure S2. View of the stacking mode of the sheets and the interlamellar separation in compound 1; Page S4.

6. Figure S3. View of the two sorts of circuits I and II, as well as the three kinds of conformations of bbi ligands in the ladderlike double-chain of 4; Page S4.

7. Figure S4. ORTEP plot of the asymmetric unit of 5; Page S4.

8. Figure S5. The stepwise schematic illustrations of the construction of the $3 \mathrm{D}$ network in 5; Page S5-S7.

9. Figure S6. View of the five sorts of conformations of bbi ligands in the flexible $\left[\mathrm{Cu}(\text { bbi) }]_{\mathrm{n}}\right.$ chain of $\mathbf{5}$; Page $\mathrm{S} 7$.

10. Figure S7. View of the three sorts of bigger circuits in compounds $\mathbf{1}(\mathrm{a}), \mathbf{4}(\mathrm{b})$ and 5(c); Page S7.

11. Figure S8. The temperature dependence of molar magnetic susceptibility $\chi_{M}$ and the product $\chi_{M} T$ for 3. Page S8.

12. Figure S9. The plot of M vs. H for compound 1; Page S8.

13. Figure S10. The plot of M vs. H for compound 2; Page S9.

14. Figure S11. The plot of M vs. H for compound 3; Page S9.

15. Figure S12. IR spectra for compounds 1-5; Page S9-S10. 
The comparison of powder X-ray diffraction of compound $\mathbf{3}$ with that of compound 1

The X-ray powder diffraction (XRPD) patterns was recorded on a Siemens D5005 diffractometer with $\mathrm{Cu} \mathrm{K} \alpha(\lambda=1.5418 \AA)$ radiation. A scan was performed in the $5<2 \theta<50^{\circ}$ range. The XRPD of $\mathbf{3}$ (black line) is mostly consistent with the simulated diffraction of $\mathbf{1}$ (red line).

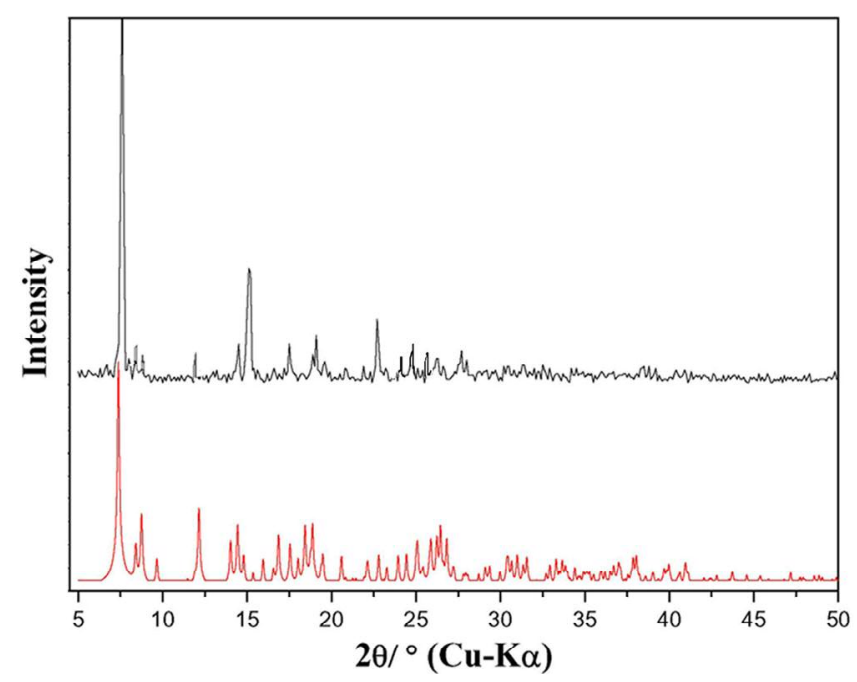

The confirmation of the molecular formulas

The confirmation of the molecular formulas is based upon the bond valence sum calculations $\left(\sum_{\mathrm{s}}\right)$ and the charge balance. For compounds 1, $\mathbf{2}$ and 4, the oxidation states of all the $\mathrm{V}$ atoms are $+4\left(\sum_{\mathrm{s}}=4.13-4.16, \mathbf{1} ; \sum_{\mathrm{s}}=4.03-4.19, \mathbf{2} ; \sum \mathrm{s}=3.95-4.43,4\right)$ and of all the As atoms are $+3\left(\sum \mathrm{s}=3.06-3.09,1 ; \sum \mathrm{s}=3.02-3.07,2 ; \sum \mathrm{s}=3.02-3.41,4\right)$. Therefore, the $\left\{\mathrm{As}_{8} \mathrm{~V}_{14} \mathrm{O}_{42}\right\}$ cluster presents an approximately charge of -4 . The oxidation states of all the $\mathrm{Cu}$ atoms in $\mathbf{4}$ are $+1\left(\sum_{\mathrm{s}}=1.19,1.04,0.87\right.$ and 0.88 for $\mathrm{Cu} 1$, $\mathrm{Cu} 2, \mathrm{Cu} 3$ and $\mathrm{Cu} 4$ respectively). For compound $\mathbf{5}$, the oxidation states for the sixteen $\mathrm{V}$ atoms are 4.21, 4.62, 4.71, 4.71, 4.36, 4.36, 4.39, 4.72, 4.48, 4.17, 4.15, 4.64, 4.49, 4.12, 4.69 and 4.65, respectively, and for the six $\mathrm{Cu}$ atoms are 1.05, 0.93, 0.97, 1.03, 
1.09 , and 1.00 , respectively. The total sum of sixteen $\mathrm{V}$ is 71.47 . Thus the $\left\{\mathrm{V}_{16} \mathrm{O}_{38} \mathrm{Cl}\right\}$ cluster has a calculated charge of -5.53 , which is approximately balanced by six $\mathrm{Cu}(\mathrm{I})$ ions.

\section{Thermogravimetric analyses}

TG analyses were performed on a Perkin-Elmer TGA7 instrument in flowing $\mathrm{N}_{2}$ at a heating rate of $10{ }^{\circ} \mathrm{C} \min ^{-1}$. The TGA curves of $1-4$ all exhibit two major mass losses in the regions of $40-190{ }^{\circ} \mathrm{C}$ and $220-1000{ }^{\circ} \mathrm{C}$ (see the following figures). The first step corresponds to the loss of one water molecules and the second huge mass loss can be assigned to the loss of four ligand bbi molecules and the sublimation of four $\mathrm{As}_{2} \mathrm{O}_{3}$ molecules. Assuming that the residue corresponds to $\mathrm{VO}_{2}$ and each metal oxides, the observed total weight loss $(55.55 \%$ for $\mathbf{1}, 55.84 \%$ for $2,55.61 \%$ for 3 and $51.63 \%$ for 4$)$ is consistent with the calculated value $(54.50 \%, 54.51 \%, 54.25 \%$ and $52.03 \%$, respectively).

The TG curve of 5 gives a total loss in two steps of $38.58 \%$ in the range of $320-900$ agrees well with the calculated value of $39.43 \%$. The fist weight loss at $320-486{ }^{\circ} \mathrm{C}$ represents the loss of five ligand molecules. The second step between 486 and $900{ }^{\circ} \mathrm{C}$ relates to the loss of one ligand molecule.
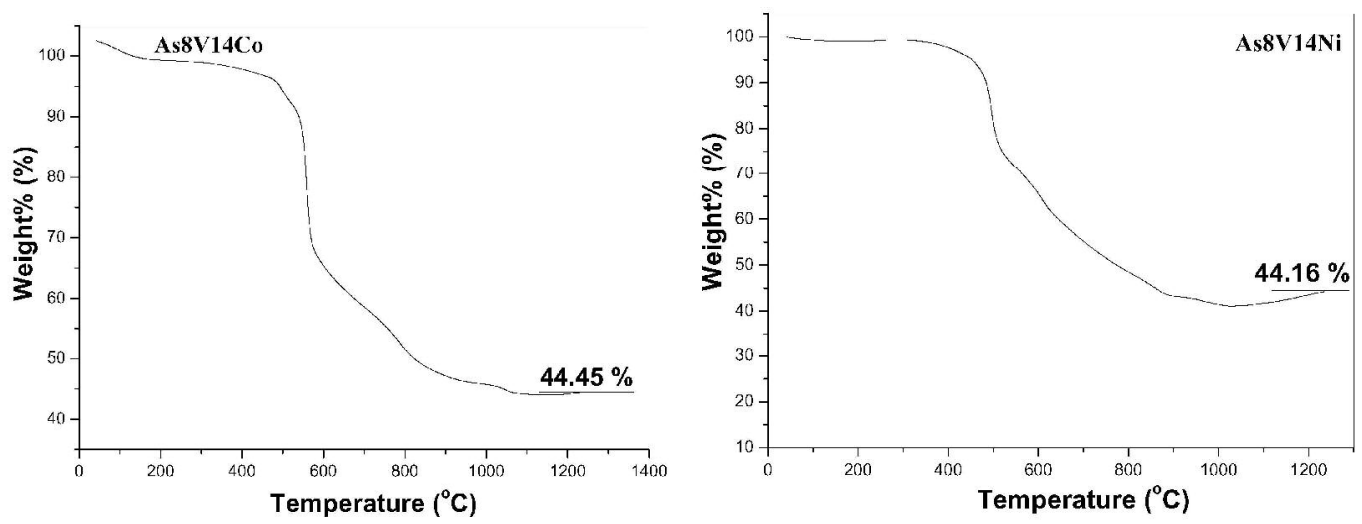

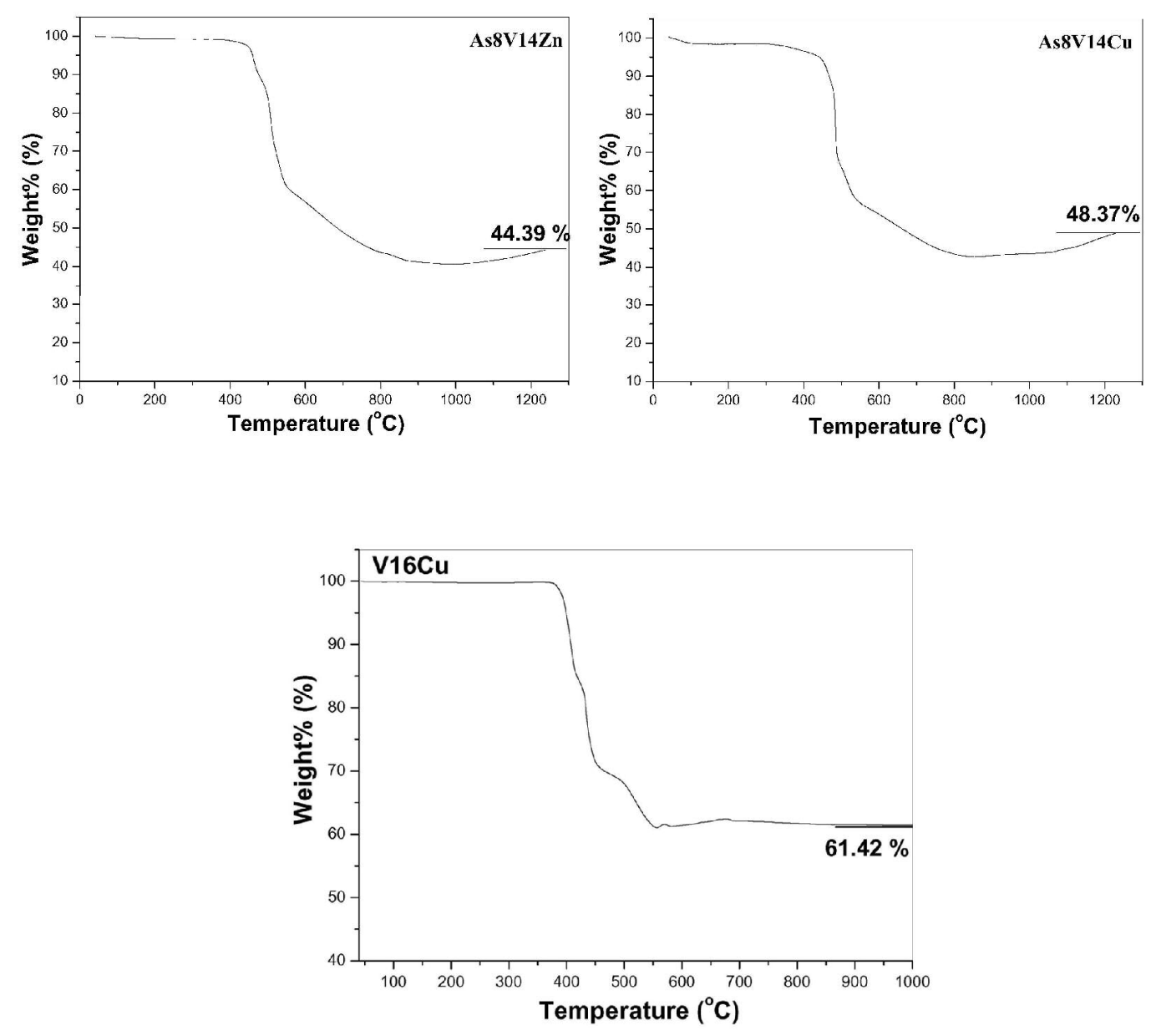

Figure S1. Illustration of the two sorts of four-membered circuits of

$\mathrm{Co}_{4}(\mathrm{bbi})_{4}$ in $\mathbf{1}$ with dimensions of $c a .15 .1 \AA \mathrm{x} 15.1 \AA$ for $\mathbf{I}$ and $c a .5 .9 \AA$ x $5.9 \AA$ for II.

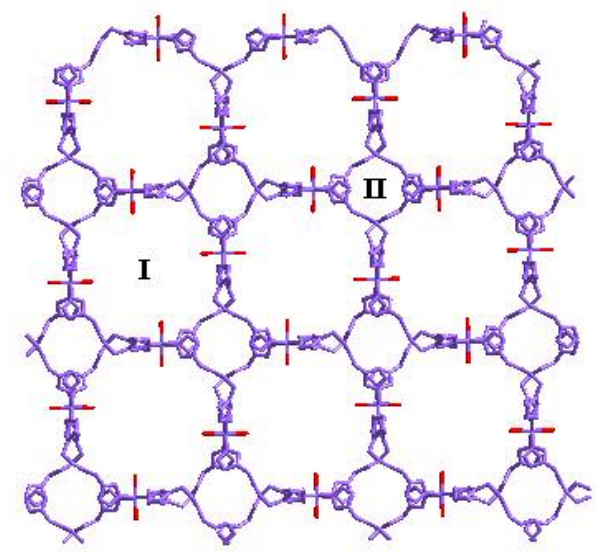


Figure S2. View of the stacking mode of the sheets and the interlamellar separation in compound $\mathbf{1}$.

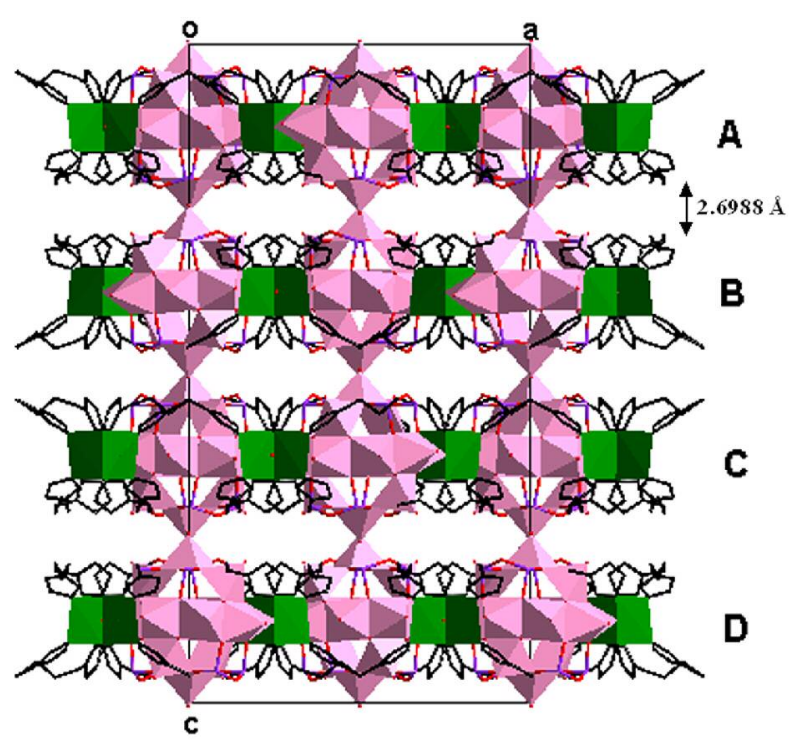

Figure S3. View of the two sorts of circuits I and II, as well as the three kinds of conformations of bbi ligands in the ladderlike double-chain of 4 .

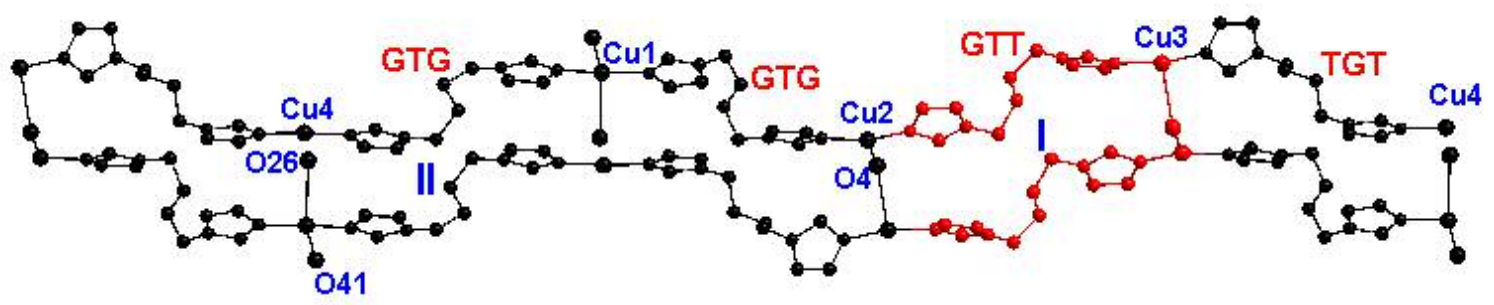

Figure S4. ORTEP plot of the asymmetric unit of $\mathbf{5}$.

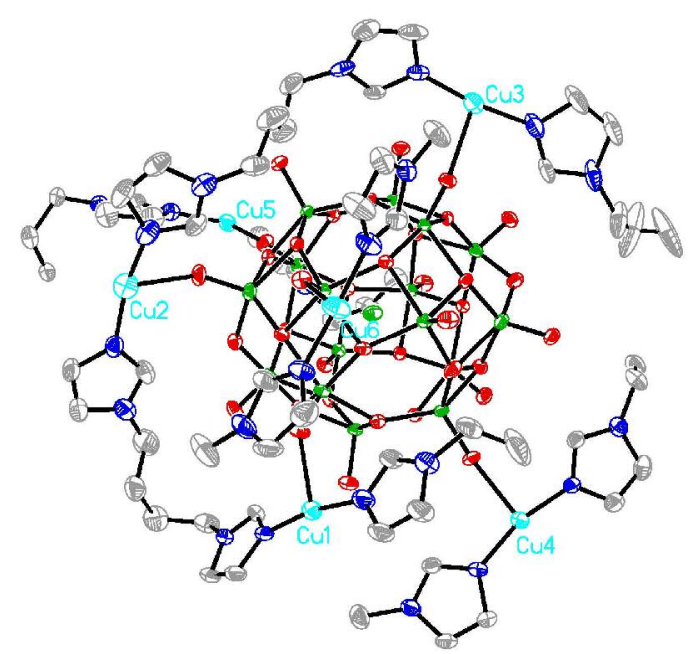


Figure S5. The stepwise schematic illustrations of the construction of the 3D network in 5: (a) The inorganic zigzag chain; (b) The 2D network containing zigzag chains; (c) View of the linkages of binuclear $\left\{\mathrm{Cu}_{2}(2) \mathrm{O}_{2} \mathrm{~N}_{4}\right\}$ and $\left\{\mathrm{Cu}_{2}(5) \mathrm{O}_{2} \mathrm{~N}_{4}\right\}$ as well as the multiple metalorganic connections of $-\mathrm{Cu} 1-\mathrm{bbi}-\mathrm{Cu} 2-,-\mathrm{Cu} 2-\mathrm{bbi}-\mathrm{Cu} 3-,-\mathrm{Cu} 5-\mathrm{bbi}-\mathrm{Cu} 6-$, -Cu1-bbi-Cu1- and -Cu4-bbi-Cu4- in the layer; (d) The layer illustrated in Mercury; (e) Horizontal view of the layer in Mercury; (f) View of the 3D framework constructed by multiple layers; (g) View of the linkages of metalorganic segments of $-\mathrm{Cu} 3-\mathrm{bbi}-\mathrm{Cu} 6-$ and -Cu4-bbi-Cu5- between the layers.

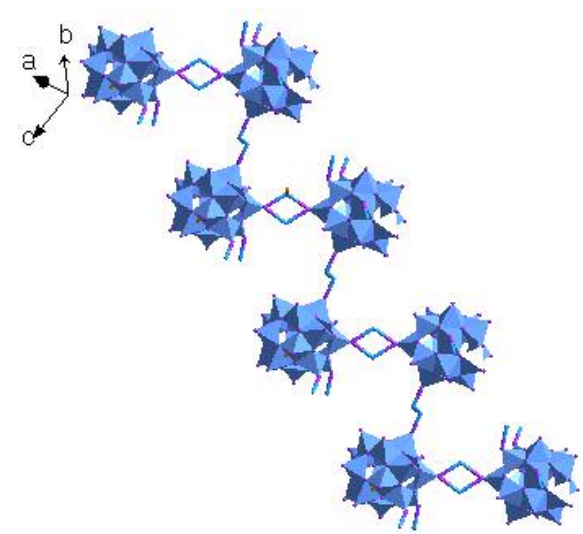

(a)

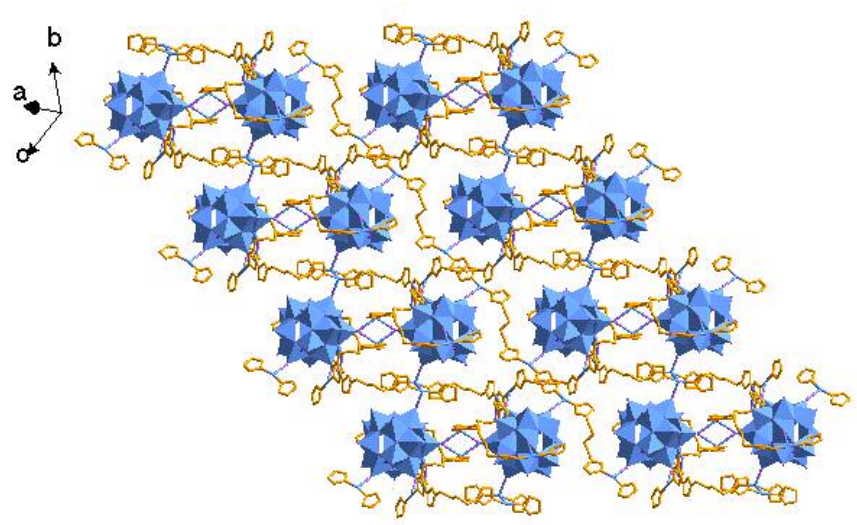

(b)

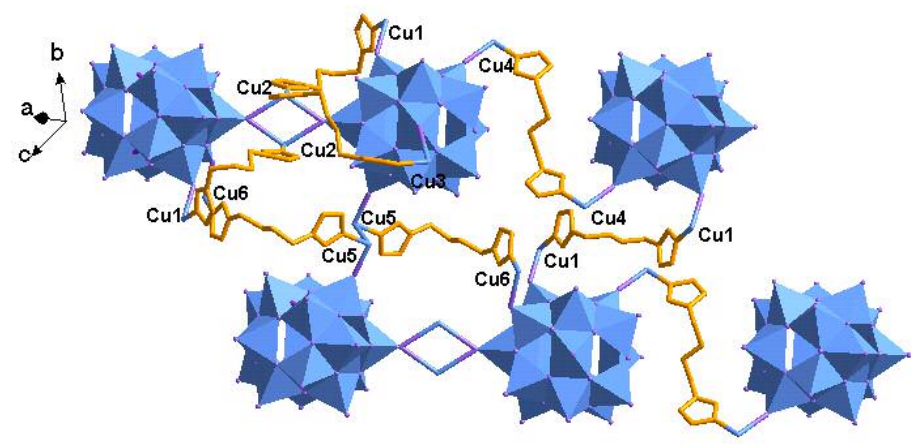

(c) 


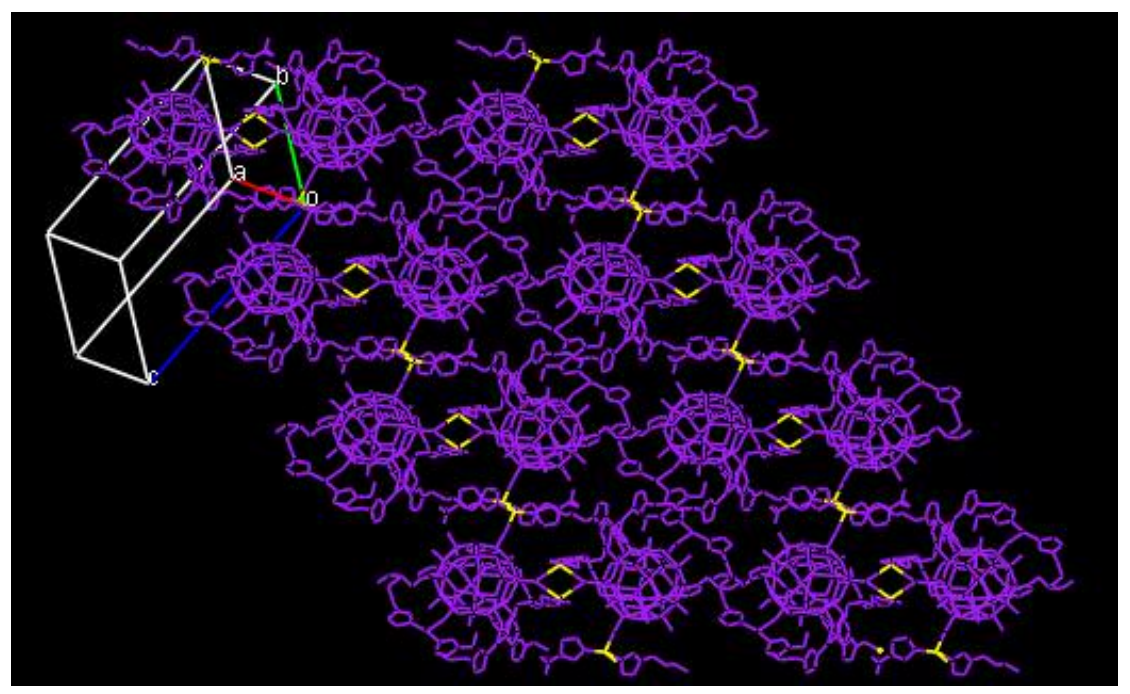

(d)

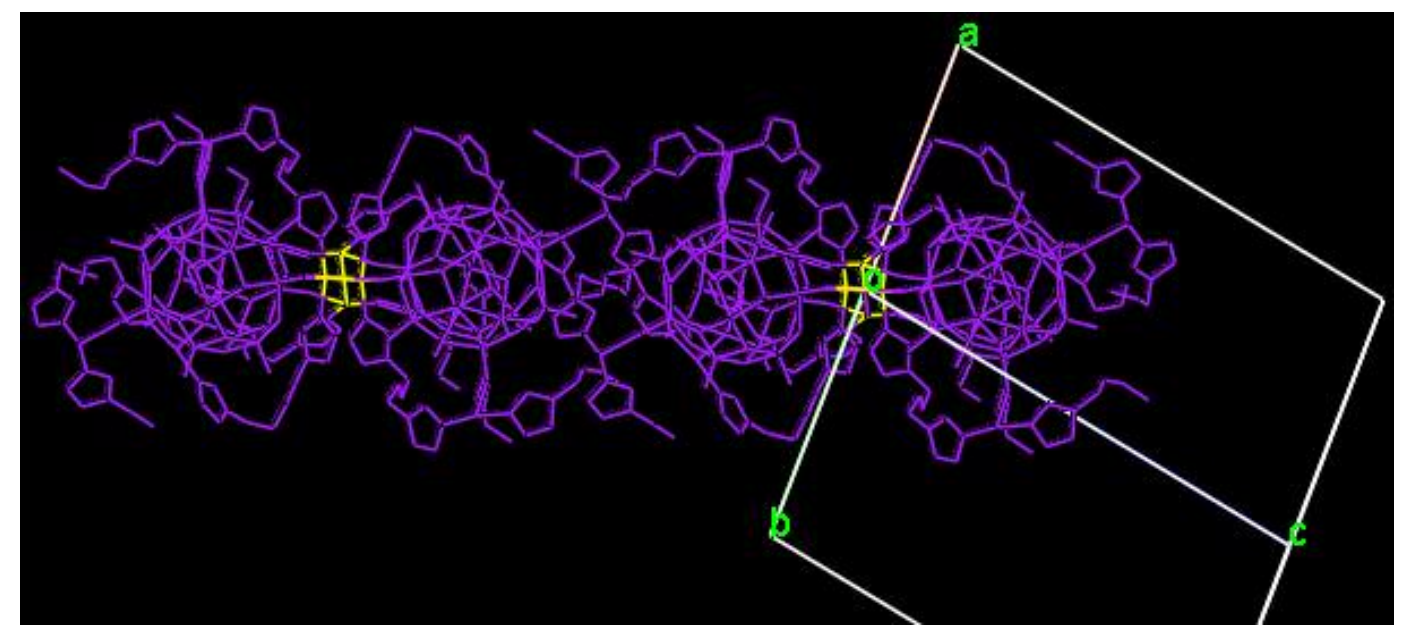

(e)

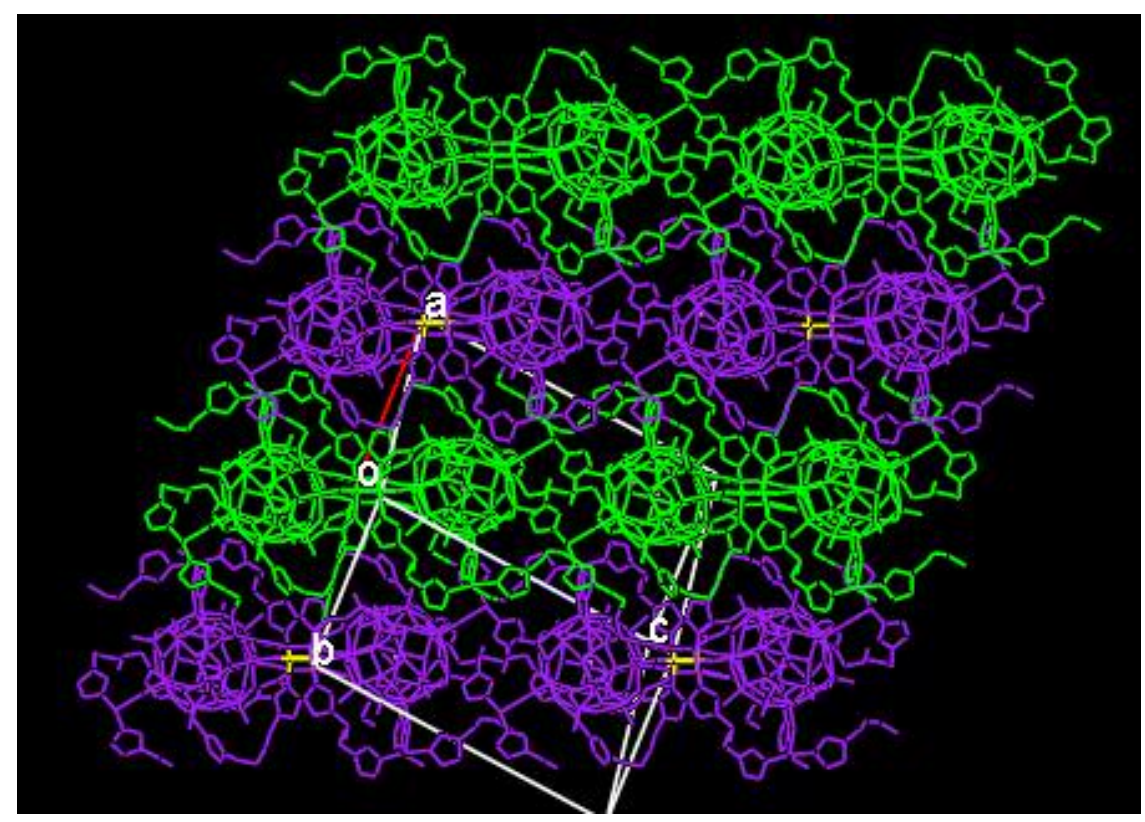

(f) 


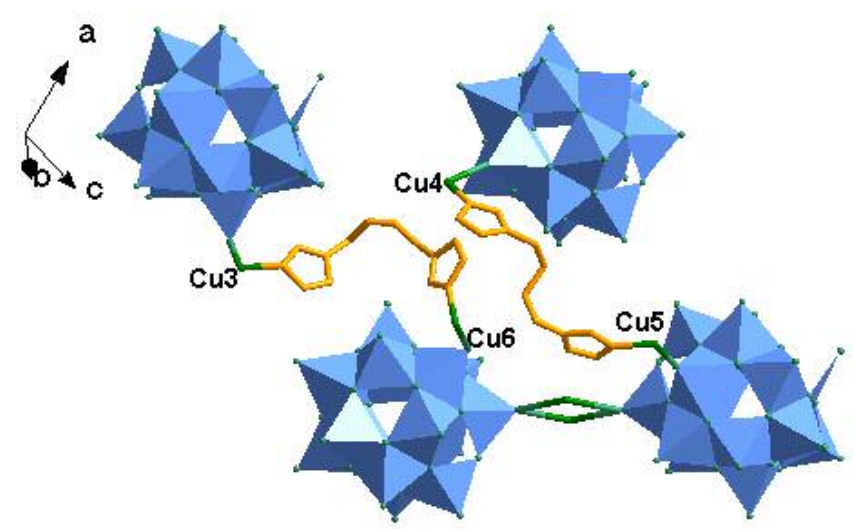

(g)

Figure S6. View of the five sorts of conformations of bbi ligands in the flexible $[\mathrm{Cu}(\mathrm{bbi})]_{\mathrm{n}}$ chain of 5 .

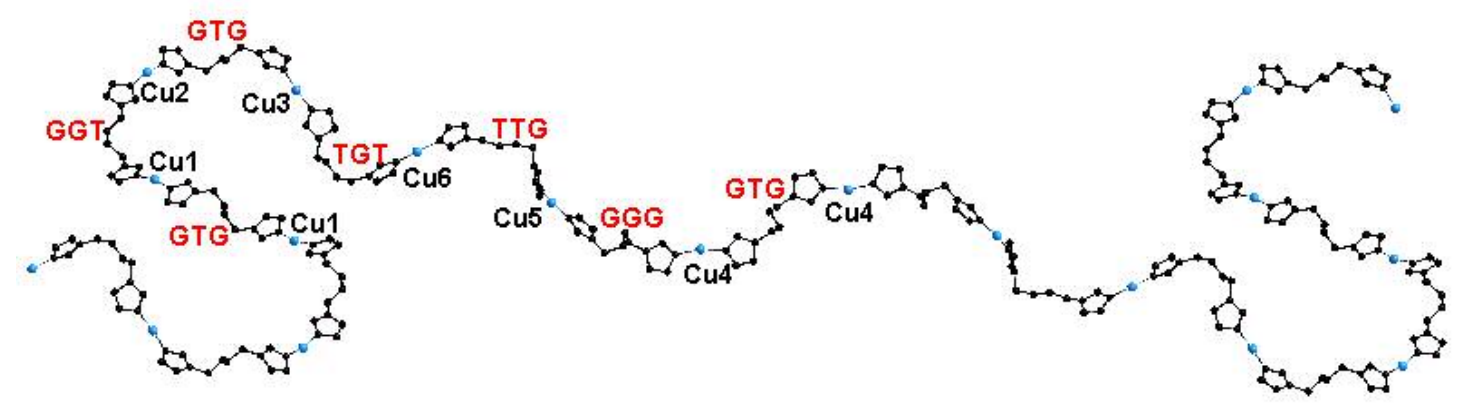

Figure S7. View of the three sorts of bigger circuits in compounds 1(a),

$$
\text { 4(b) and 5(c). }
$$

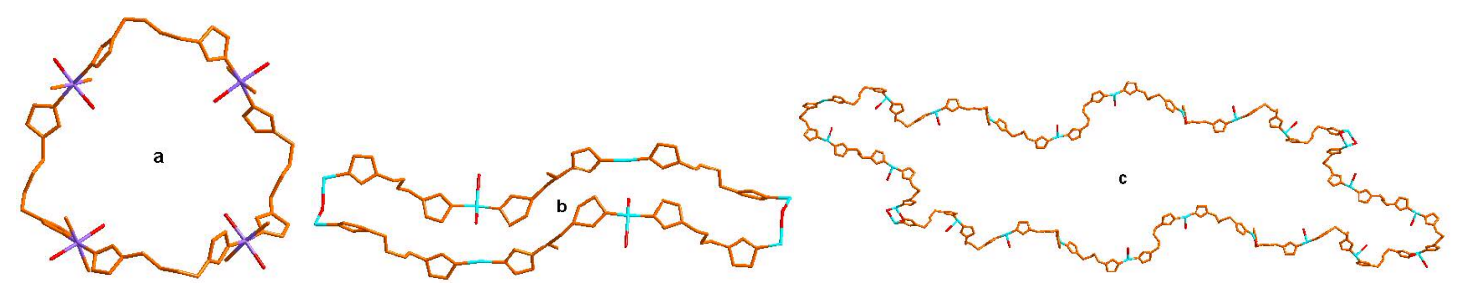


Figure S8. The temperature dependence of molar magnetic susceptibility $\chi_{M}$ and the product $\chi_{M} T$ for $\mathbf{3}$.

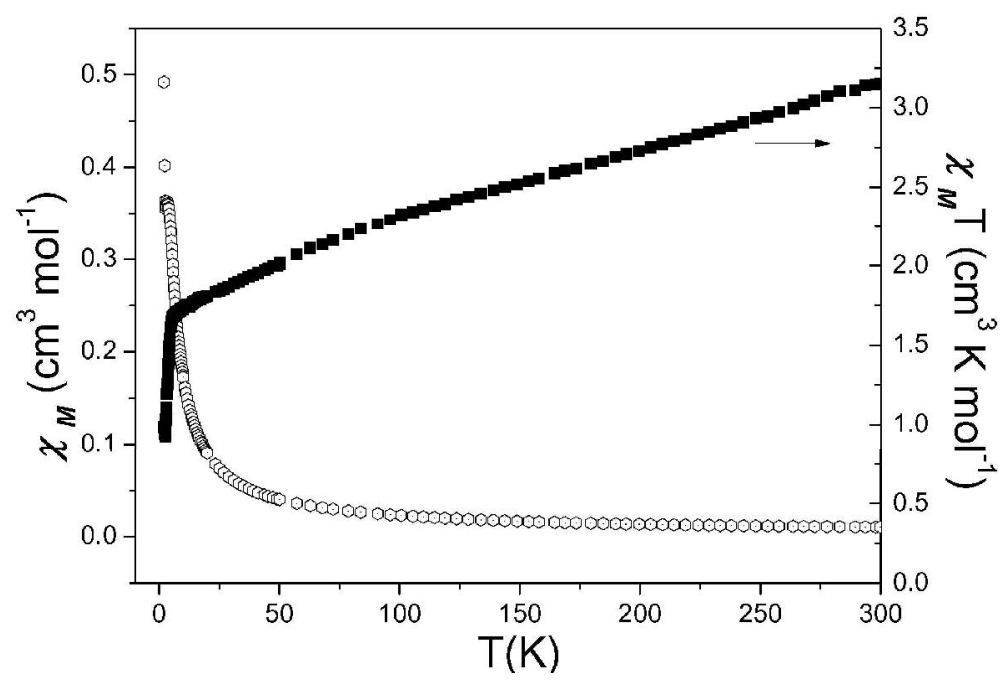

Figure S9. The plot of M vs. H for compound 1.

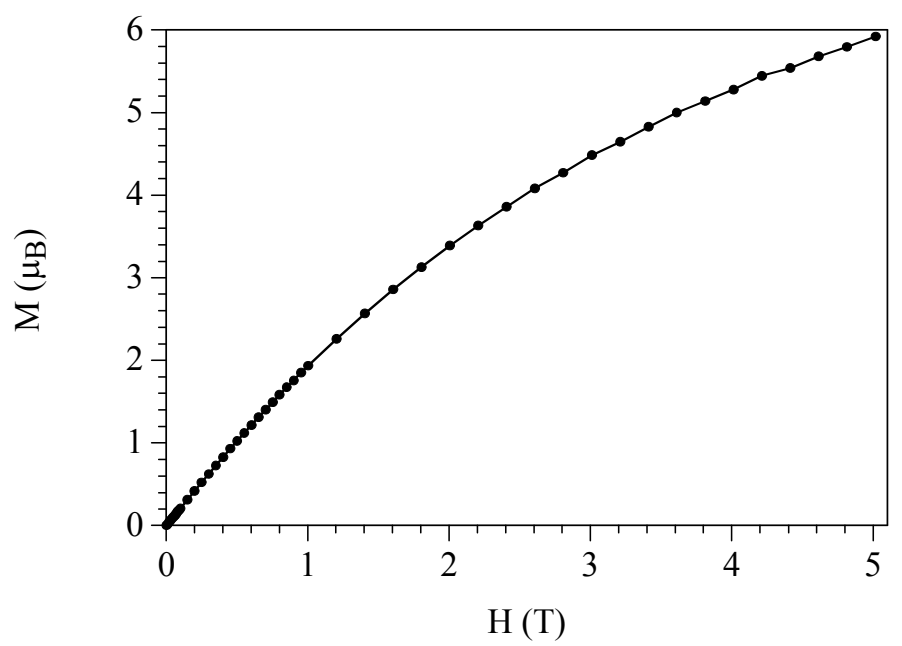


Figure S10. The plot of M vs. H for compound 2.

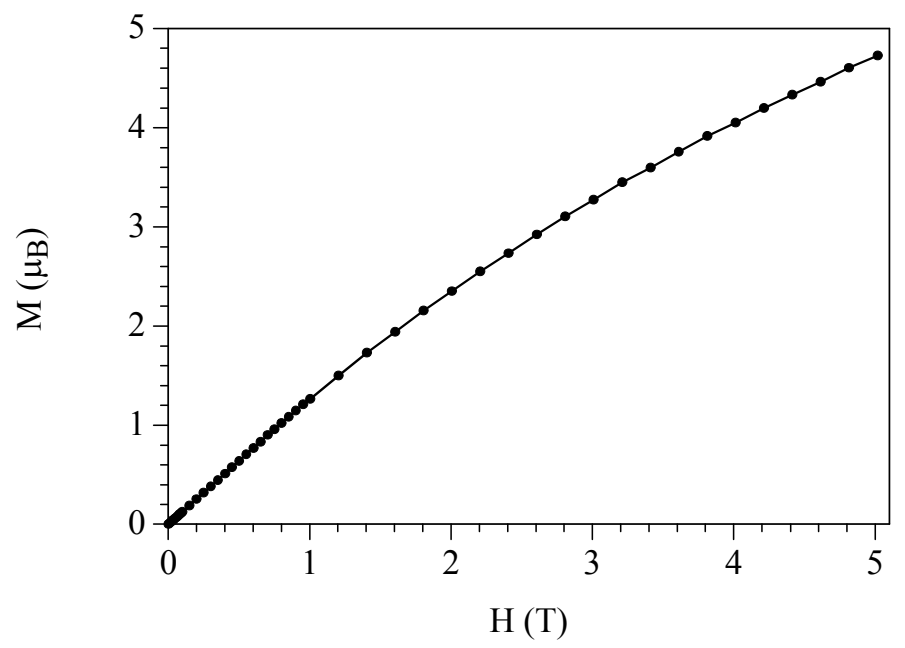

Figure S11. The plot of M vs. H for compound 3.

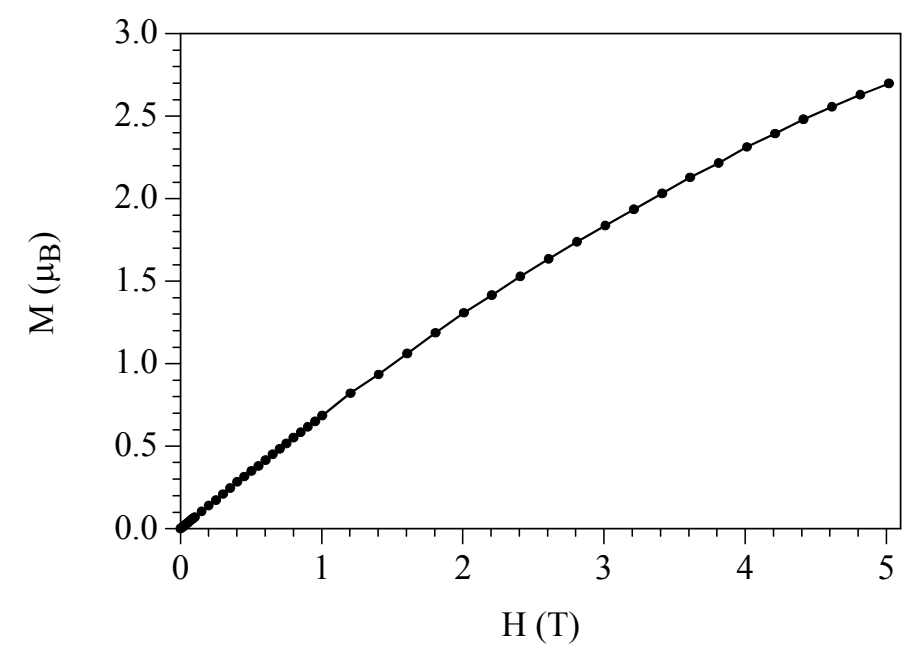

Figure S12. IR spectra for compounds 1-5.
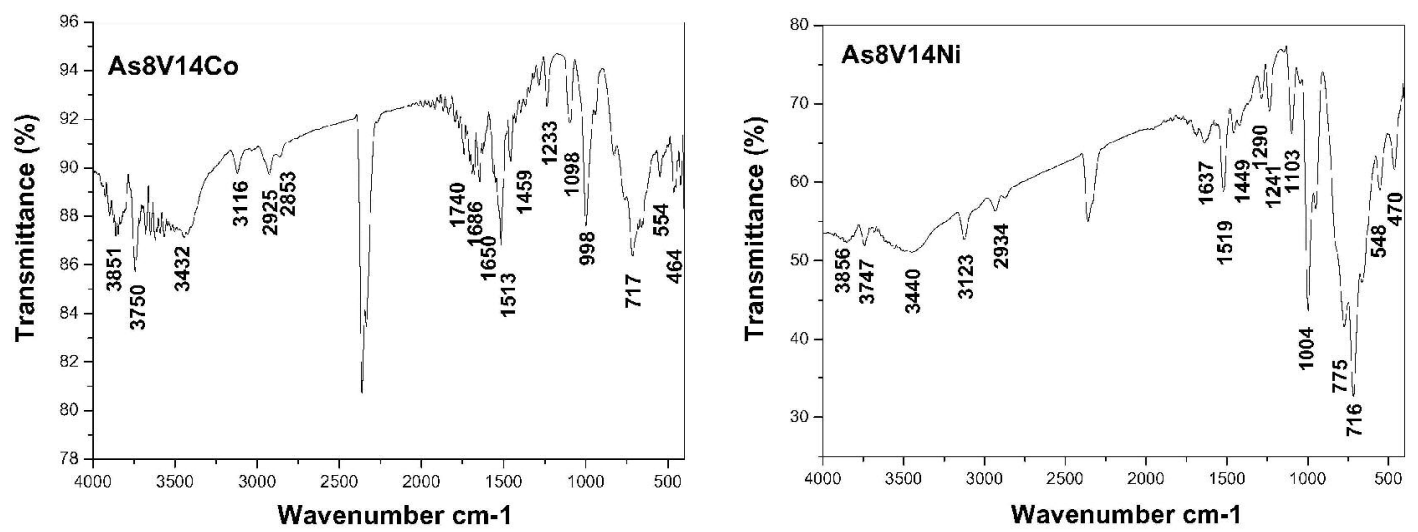

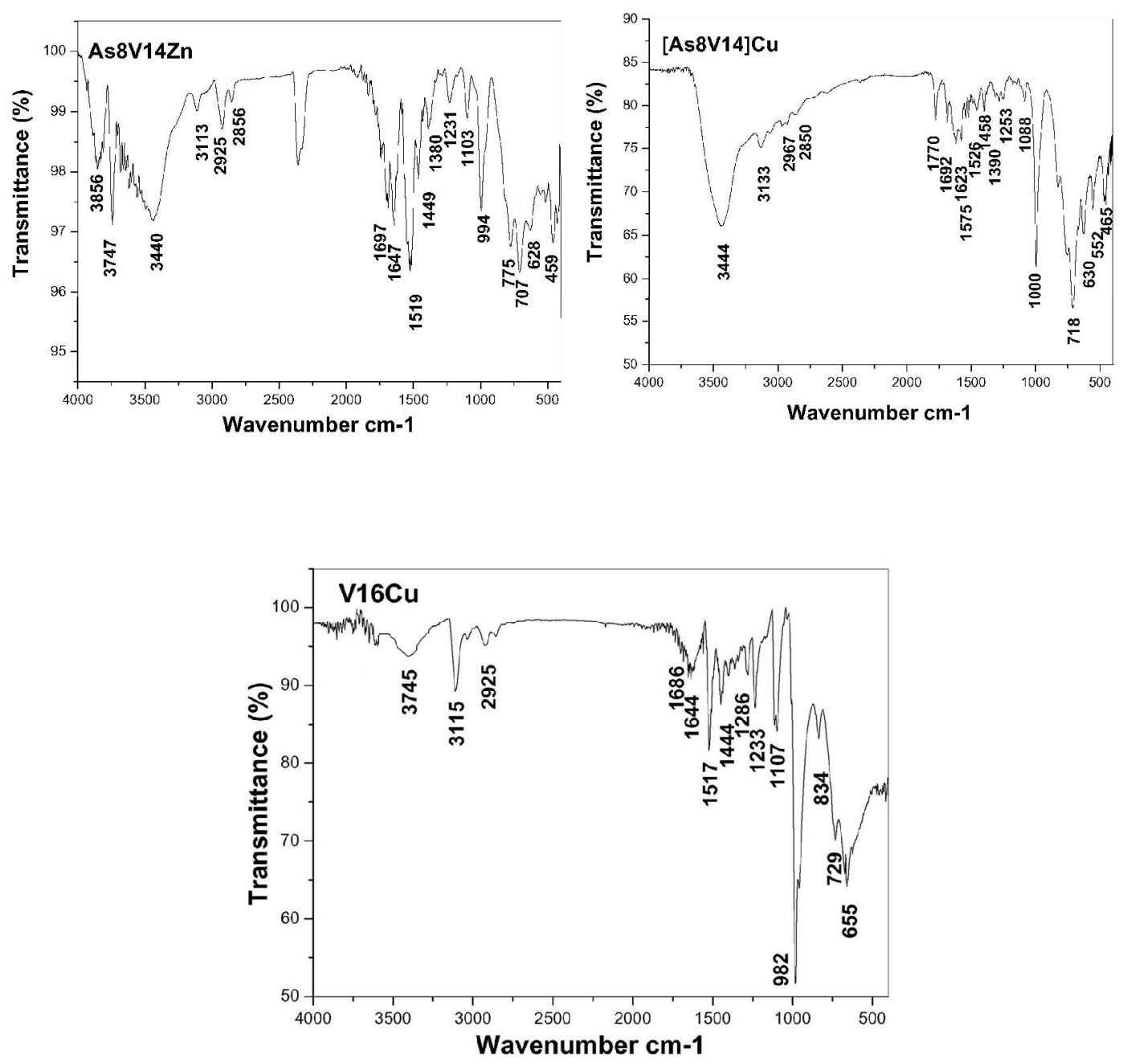